\title{
Colorectal carcinogenesis in germ-free and conventionally reared rats: Different intestinal environments affect the systemic immunity
}

\author{
LUCA VANNUCCI, RENATA STEPANKOVA, HANA KOZAKOVA, ANNA FISEROVA, \\ PAVEL ROSSMANN and HELENA TLASKALOVA-HOGENOVA \\ Department of Immunology and Gnotobiology, Institute of Microbiology, \\ Academy of Sciences of the Czech Republic v.v.i., Videnska 1083, 14220 Prague 4, Czech Republic
}

Received October 2, 2007; Accepted December 11, 2007

\begin{abstract}
Intestinal microbiota are considered to play an important role both in colorectal tumor development and in the modulation of mucosal immunity. Studies on animals reared in germ-free (GF, without intestinal microbiota) versus conventional $(\mathrm{CV}$, with regular microbiota colonization of the bowel) conditions can aid in clarifying the influence of bacteria on carcinogenesis and the anticancer immune response. The capability of the intestinal environment to modulate anticancer immunity not only at the mucosal but also at the systemic level is still an open question. In our study we found that, following the same protocol of colorectal cancer induction, GF rats developed less and smaller tumors than $\mathrm{CV}$ rats. The GF rats that did not develop cancer also presented a better anticancer immune response with an increase in NK, NKT, CTL, B cells and cytotoxicity in peripheral blood. We hypothesize that the lower antigenic challenge and the absence of the 'physiological inflammation', caused by the commensal microbiota in the gut of CV rats, may enhance the capability of the GF rats to develop more efficacious anticancer immune responses. The different levels of tolerance/ regulatory mechanisms in GF versus the $\mathrm{CV}$ animals may modulate the anticancer response not only at the mucosal but also at the systemic immunity level.
\end{abstract}

Correspondence to: Dr Luca Vannucci, Laboratory of Natural Cell Immunity, Department of Immunology, Institute of Microbiology, Academy of Sciences of the Czech Republic, Videnska 1083, 14220 Prague 4, Czech Republic

E-mail: vannucci@biomed.cas.cz

Abbreviations: FACS, fluorescence-activated cell sorter; CD, cluster of differentiation; FITC, fluorescein isothiocyanate; PE, phycoerythrin; IFN, interferon; IL, interleukin; APC, antigenpresenting cell

Key words: colorectal neoplasms, immunity, germ-free animals, carcinogenesis, microbiota

\section{Introduction}

Colorectal cancer is an illness with a strong social impact. It is the second cause of death by cancer worldwide, and is the cause of $12 \%$ of the cancer deaths in the European Union (1). Environmental factors, especially dietary habits and intestinal microbiota composition, are claimed to be critical for tumor induction, promotion and development, independently of the genetic background on which they can operate (hereditary or sporadic cancers) (2-4).

Intestinal bacterial flora has been described to play a double-edged activity, according to its composition and metabolic products, either assisting or preventing carcinogenesis (4-6). Consequently, understanding the role of the microbiota in this process is important for the development of effective probiotic- and prebiotic-based anticancer therapies and prevention strategies (7-9).

Moreover, the various types of bacteria can modulate differently the gut-associated lymphoid tissue (GALT) functions (10-13). In fact, to preserve the local homeostasis, the mucosal immunity i) is constantly activated to impede the translocation of the bacteria through the mucosa ('physiological inflammation'); ii) has an active cross-talk with the bacterial environment in a symbiotic mode; iii) has the ability to distinguish pathogens from commensal microflora; and 4) to preserve the symbiotic balance, permits tolerance toward immunogenic molecules expressed or produced by the commensal microflora. Consequently, the intestinal environment can develop an intense modulatory effect on immunity both at the local (mucosal) and the systemic level (14-17). Accordingly, the presence or absence of intestinal bacteria can induce a different modulation of the anticancer response, not only at the mucosal but also at the systemic level.

Animal models of human diseases greatly contribute to the elucidation of the etiology and pathogenesis of illnesses and to the development of new approaches to diagnosis and therapy $(18,19)$. A large number of mouse and rat models have been proposed for studying colorectal carcinogenesis. Many of these models use chemical carcinogens as cancer inducers. Azoxymethane and 1,2-dimethylhydrazine are the carcinogens most commonly utilized. They affect DNA methylation, and can be used alone or in association with orally administered 
promoters (e.g. a fatty diet, dextran sulfate) (20-23). We developed a model, previously published, in which the initiation by azoxymethane is followed by promotion with repeated injections of a known quantity of bile inside the cecum $(24,25)$. In fact, bile can affect the composition of the intestinal microbiota and, reciprocally, the microbiota can elaborate the biliary salts with effects on cancer development (26,27).

The availability of gnotobiologic animals generated and maintained in germ-free conditions has enhanced the possibility to investigate and understand the impact of the intestinal environment on both the modulation of mucosal immunity and the onset of pathologies such as inflammatory bowel diseases and colorectal cancer (28).

In this study we present results concerning colorectal cancer development following a common protocol of experimental carcinogenesis in conventionally reared and germ-free Wistar-AVN rats. Under these conditions, we also investigated the influence of the different intestinal environments on the systemic immunity (lymphocyte subpopulation profile and cytotoxic response) in healthy, cancer-bearing (CR), and cancer-resistant animals.

\section{Materials and methods}

Experimental animals. Male inbred Wistar-AVN (F 89) rats were received as pathogen-free from the animal facility of the Institute of Physiology, Academy of Sciences of the Czech Republic, v.v.i. (ASCR, v.v.i.), in Prague.

This inbred strain was originally established at the Institute of Genetics of the Czechoslovak Academy of Sciences (70 generations) since 1980 (29), and then maintained at the Institute of Physiology, ASCR, v.v.i. The conventional (CV) rats, with regular intestinal commensal microflora, were housed in the animal facility of the Institute of Microbiology, ASCR, v.v.i., in Prague. They were fed an unrestricted standard pellet (ST-1) diet and had free water intake.

The Wistar-AVN germ-free (GF) rats were produced in the Laboratory of Physiology, Immunity and Ontogenesis of Gnotobionts of the Institute of Microbiology, ASCR, v.v.i., in Novy Hradek (CZ). Females at the end of pregnancy underwent hysterectomy. The newborns were delivered by Cesarean section after washing the uterus in antiseptic solution, and were transferred inside a sterile transparent Trexler-type plastic isolator. The newborns were maintained under controlled sterile conditions and reared inside the isolators (30). Initially, the rats were artificially hand-fed (every 3-4 h) with a specifically formulated milk diet, subsequently substituted by a granulated diet (30-33). All nutrients were regularly sterilized by irradiation ( $59 \mathrm{kGy}$ ). Throughout the experiment, the GF rats were maintained inside the sterile isolators, at a constant temperature of $22^{\circ} \mathrm{C}$, under filtered air flux, and without restriction in diet and water intake (Fig. 1).

A regular weekly control of the sterile conditions was performed by sampling stools from the isolators. Samples were cultivated on peptone bouillon, Sabouraud bouillon, Schadller bouillon (Difco, Detroit, MI, USA) and then on blood agar, Sabourad agar, Schadller agar in an anaerobic atmosphere (gas Anaerogen 2.5 1:DIOXO) to detect the presence of both aerobic and anaerobic bacteria. Furthermore, the smears were stained with the Gram stain and the fluorescent dyes acridine orange (for Gram-positive bacteria, yellow fluorescence) and fluorescein (for Gram-negative bacteria, green fluorescence) (34).

Carcinogen and promoter. Azoxymethane (AOM), an active derivative of 1-2-dimethylhydrazine, was used as the chemical carcinogen and porcine bile was used as the promoter. Both products were purchased from Sigma Chemicals (Seattle, WA, USA). The dry porcine bile was solubilized in water $(1500 \mathrm{mg}$ of dry bile in $100 \mathrm{ml}$ sterile distilled water, stirred at $1000 \mathrm{rpm}$ for $1 \mathrm{~h}$ at $40^{\circ} \mathrm{C}$ ) and then filtered through $0.22-\mu \mathrm{m}$ sterile micropore filters (Millex-GS Filters, Millipore, Bedford, MA, USA) to eliminate possible bacterial contamination.

Monoclonal antibodies. The panel of monoclonal antibodies used for the identification of the lymphocyte subpopulation phenotypes included anti-CD3 (G4.18), -CD4 (OX-38), -CD8a (OX-8), -CD8b (341), -TCR $\alpha \beta$ (R73), -CD45ra (OX-33), either FITC- or PE-labeled; biotin-conjugated anti-NKP-P1A (X.78) and streptavidin labeled with appropriate fluorescent dye. All antibodies were purchased from Pharmingen, San Diego, CA, USA.

Animal model and experiment design. Thirty-two rats (10 GF induced to cancer, $10 \mathrm{CV}$ induced to cancer, $6 \mathrm{GF}$ healthy controls, $6 \mathrm{CV}$ healthy controls) were used for the experiments. The animals were sacrificed in the $32 \mathrm{nd}$ week from the beginning of the experiment. Three independent experiments were performed.

Colorectal carcinogenesis was induced as previously published (24,25). Briefly, CV and GF male rats, $150 \mathrm{~g}$ body weight (b.w.), were operated on under general anesthesia (chloralium hydrate $0.8 \%, 1 \mathrm{ml} \mathrm{IP} / 150 \mathrm{~g}$ b.w.), to create a subcutaneous cecal hernia (Fig. 2). In the rat, the appendix and cecum are very large and constitute a continuous intestinal tract. The GF rats present a larger cecum than the CV rats, with a thinner intestinal wall.

The apical part of the appendix, passed through an opening created in the lower-right abdominal wall quadrant, was fixed in a subcutaneous pocket. The resulting bulk was easy to be identified and percutaneously punctured.

Ten days after the surgery, rats received subcutaneously $9 \mathrm{mg} / \mathrm{kg}$ b.w. azoxymethane (AOM) once a week for 5 weeks (initiation). The promotion was performed by intracecal injection of $3 \mathrm{ml}$ of bile, three times a week for 3 weeks.

At the scheduled time ( 32 weeks from the beginning of the experiment), the animals were sacrificed. An autopsy was performed, and blood, the spleen, mesenteric lymph nodes, and large bowel were collected. Mononuclear cells were separated from the blood and spleen in order to be used for the FACS analysis and the cytotoxicity assay. The large bowel, longitudinally opened and washed with cold saline, was immediately examined. The number and dimensions of tumors were recorded. After fixation in $10 \%$ buffered formalin, the colon and rectum specimens were embedded in paraffin, and the histological sections were stained with haematoxylin and eosin for the histopathological diagnosis. 


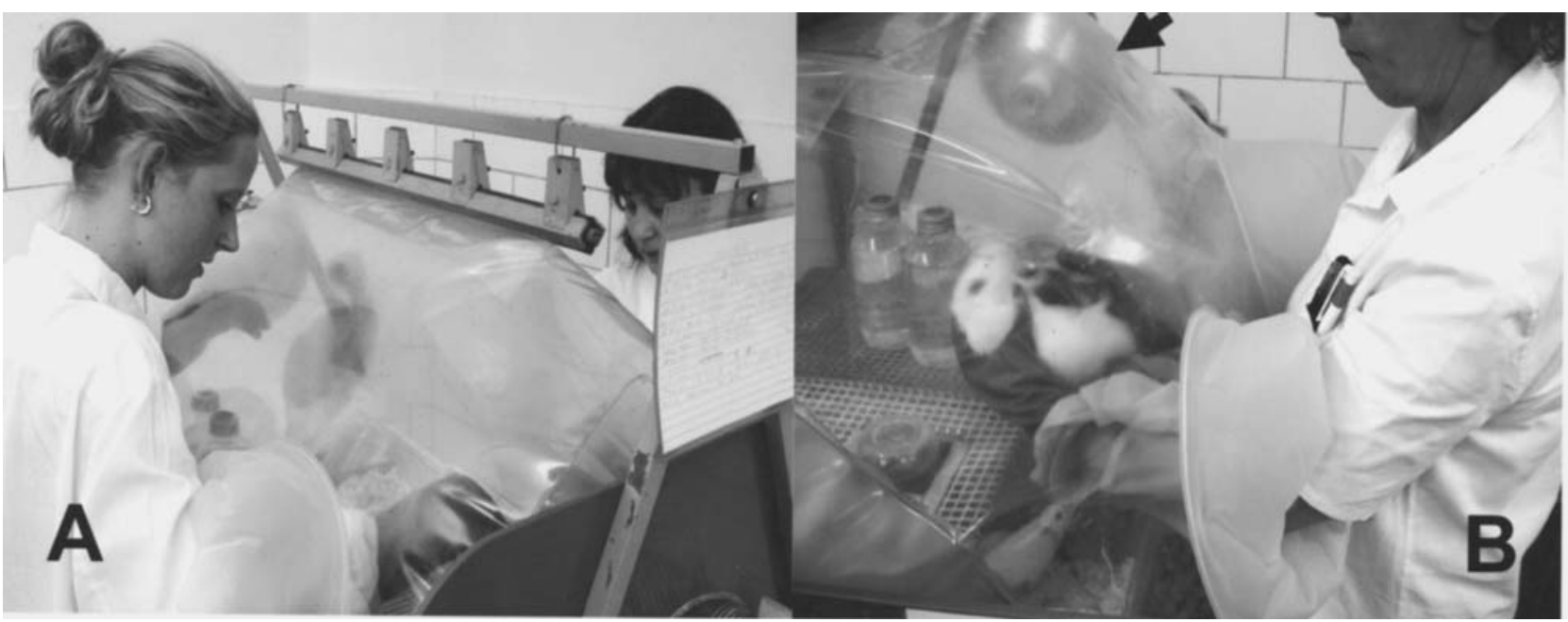

Figure 1. Rearing the germ-free rats. (A) The sterile isolator permits the simultaneous activity of two operators. (B) Manipulation of a germ-free rat inside the isolator. The air filter is visible in the upper part of the isolator (arrow).

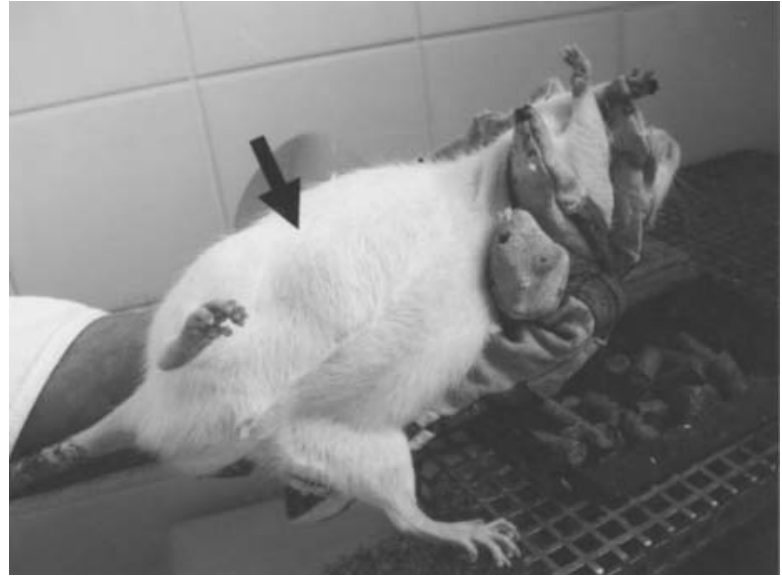

Figure 2. The cecal hernia. A Wistar-AVN rat raised under conventional conditions one month after the surgery to produce the hernia. The arrow indicates the bulk in the lower right abdomen produced by the apical part of the appendix allocated and fixed in a subcutaneous pocket. The same operation was performed on GF rats inside the isolator.

All experiments were approved by the Ethics Committee of the Institute of Microbiology, according to the Animal Protection Act of the Academy of Sciences of the Czech Republic and the European Convention for the Care and Use of Laboratory Animals.

Preparation of mononuclear cells. Rat mononuclear cells were obtained from heparinized blood and freshly harvested spleens. The spleens were dissociated using a nylon mesh. The mononuclear cells were separated by standard FicollHypaque 1085 density gradient centrifugation (400 g/30 min at $18^{\circ} \mathrm{C}$ ) and then washed three times in PBS. They were separated in the necessary aliquots after counting in a Burker's chamber and were used for the phenotype diagnosis by FACS analysis and cytotoxicity assay.

FACS analysis. The separated mononuclear cells were stained with the previously mentioned indicated panel of anti-rat monoclonal antibodies using the standard procedure in 96-well $\mathrm{U}$ bottom microtiter plates $\left(2 \times 10^{5}\right.$ mononuclear cells/well). Then they were washed once in cold wash buffer (PBS, 0.05\% $\mathrm{NaN}_{3}, 0.25 \%$ gelatine; Sigma, St. Louis, MO, USA), and appropriately diluted monoclonal antibodies were added in a $10-\mu 1$ volume. After a 20 -min incubation on ice, cells were washed 3 times with $200 \mu 1$ of wash buffer. Analysis was performed using FACS-Vantage SE flow cytometer (Becton Dickinson, San Jose, CA, USA) and FlowJo software (Treestar Inc., Ashland, OR, USA).

The lymphocyte subpopulations were identified as follows: natural killer (NK) cells (CD3-/NKR-P1Ahigh/ $\left.\mathrm{CD} \mathrm{a}^{+}\right)$; natural killer $\mathrm{T}(\mathrm{NKT})$ cells $\left(\mathrm{CD} 3^{+} / \mathrm{TCR} \alpha \beta^{+/}\right.$ NKRP1 $\left.{ }^{+}\right)$; T lymphocytes (CD3 $\left.{ }^{+} / \mathrm{TCR} \alpha \beta / \mathrm{NKR}^{-\mathrm{P}} 1^{-}\right)$; T helper $\left(\mathrm{CD}^{+} / \mathrm{CD}^{+} / \mathrm{CD} \mathrm{b}^{-}\right)$; cytotoxic $\mathrm{T}(\mathrm{CTL})$ lymphocytes $\left(\mathrm{CD} 8 \mathrm{a}^{+} / \mathrm{CD} 8 \mathrm{~b}^{+}\right)$; and B cells $\left(\mathrm{CD} 3 / \mathrm{CD} 45 \mathrm{ra}^{+}\right)(35)$.

Cytotoxicity assay. Cytotoxicity assays were performed on separated mononuclear cells as previously published (36). The effector cell activity was tested against the NK-sensitive YAC-1 cell line previously labeled with ${ }^{51} \mathrm{Cr}$ (sodium chromate, $\mathrm{Na}_{2}{ }^{51} \mathrm{CrO}_{4}$ ) using a 90 -min incubation at $37^{\circ} \mathrm{C}$ in $\mathrm{CO}_{2}$. Samples were seeded in quadruplicates. Cell-free supernatants $(0.025 \mathrm{ml} / \mathrm{sample})$ were harvested after $3.5 \mathrm{~h}$ of incubation and mixed with SuperMix scintillation cocktail (Pharmacia, P-L Biochemicals, Uppsala, Sweden) to evaluate the lysis of the target cells. ${ }^{51} \mathrm{Cr}$ release was measured in a Microbeta Trilux scintillation counter (Wallac, Turku, Finland). Results, expressed as a percentage of target cellspecific lysis, were calculated according to the standard formula:

$\%$ lysis $=($ experimental release - spontaneous release $) /$ (maximum release - spontaneous release) x 100

Statistics. Quantitative data were expressed as the mean \pm $\mathrm{SD}$, and, in appropriate cases, as percentage of the control. The Student's t-test was used for the statistical analysis of the data. 

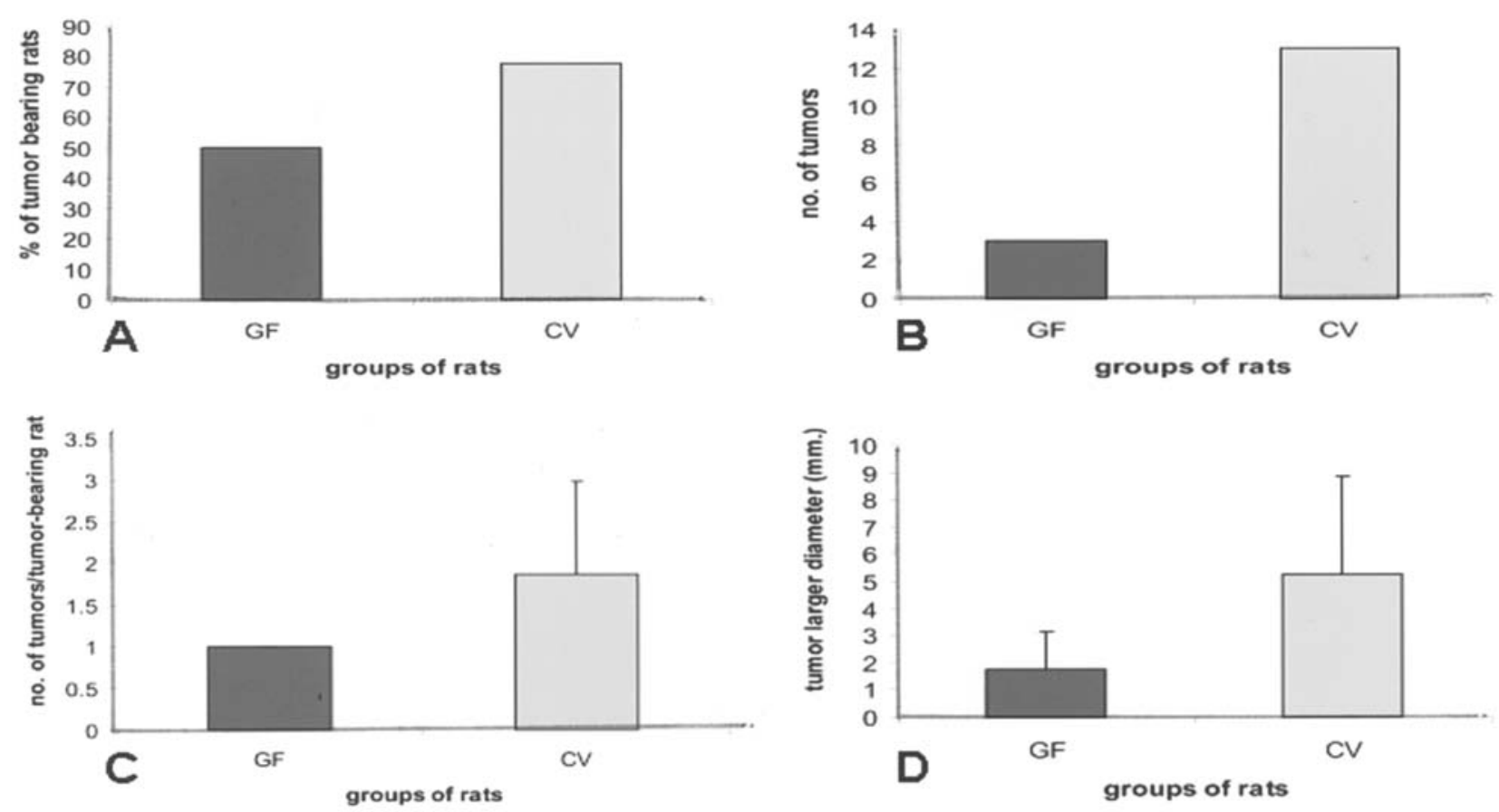

Figure 3. Tumor development in GF vs CV rats after cancer induction with AOM and bile. (A) Percentage of cancer-bearing animals per group; (B) total number of cancers per group; (C) mean cancer number per rat; and (D) mean cancer dimension per group. Tumors were immediately evaluated on fresh specimens by recording the larger diameter dimension, and then processed and examined in histological sections as described in the text.

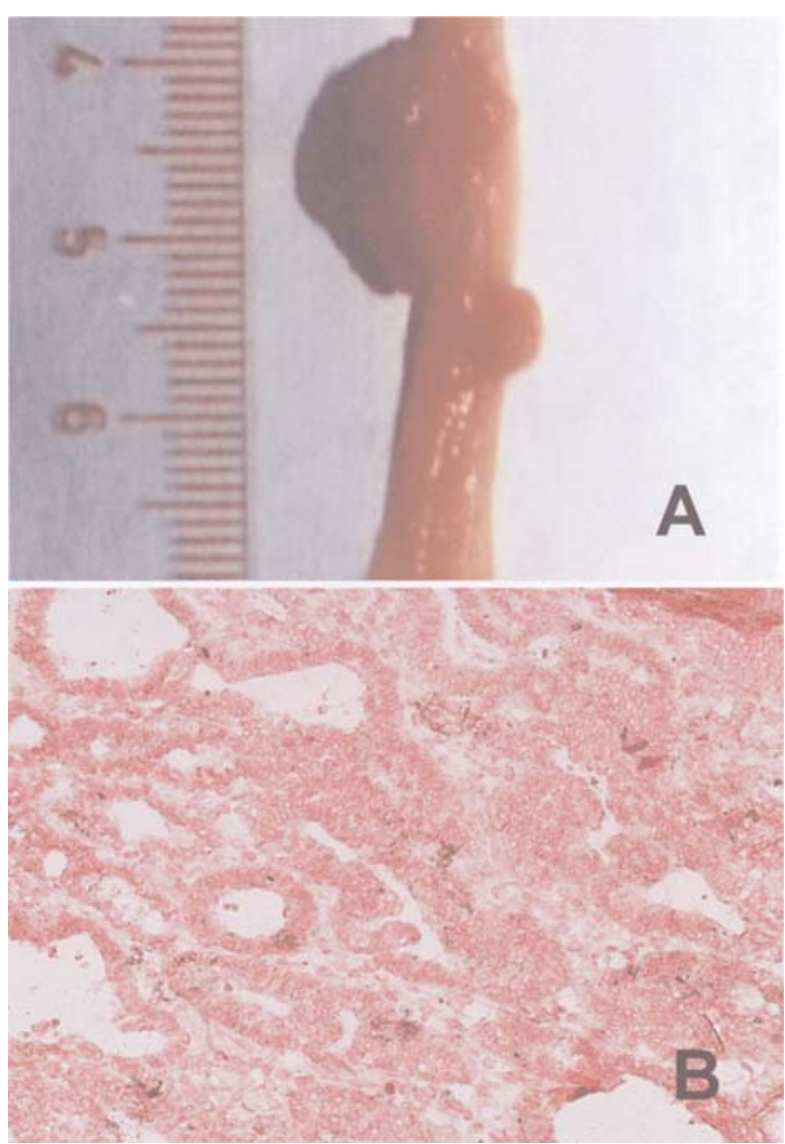

Figure 4. Colon cancer in Wistar-AVN rats. (A) Two fungating cancers in the left colon of a CV rat. (B) Moderately differentiated intestinal-type adenocarcinoma of the colon. Macroscopic and microscopic differences were found in the cancers of CV and GF animals. Only in the CV rats were more advanced stages found. Transmission light microscopy, E-E staining, x40 magnification.

\section{Results}

Tumor development. The final eligible groups of cancerinduced rats included 6 GF (2 deaths occurred during carcinogenesis induction, 2 cutaneous-cecal fistulas developed during the promotion treatment) and $9 \mathrm{CV}$ animals (1 death during carcinogenesis induction).

Cancers developed in $3(50 \%) \mathrm{GF}$ versus $7(77.77 \%) \mathrm{CV}$ rats. The total number of cancers was 3 in GF $(1 \mathrm{CR} /$ tumorbearing rat) versus 13 in $\mathrm{CV}$ ( $1.85 \mathrm{CR} /$ tumor-bearing rats) rats. Conventional rats presented not only multiple cancers, but also larger cancer dimensions (maximum tumor diameter in $\mathrm{CV}$ rats was $5.2 \pm 3.47 \mathrm{~mm}$ vs. $\mathrm{GF}, 3 \pm 1.80 \mathrm{~mm}$; $\mathrm{t}=0.45)($ Fig. 3$)$.

All animals were negative for metastatic spread. Histology revealed both intestinal and mucinous types of adenocarcinoma. The cancers $(81.25 \%)(13 / 16)$ were well-tomoderately differentiated, while the rest presented some poorly differentiated areas (Fig. 4).

As an occasional finding, $83.33 \%$ of GF rats exhibited a polycystic liver, not correlated with the presence of cancer (Fig. 5). The cysts contained a clear fluid, had diameters ranging from 1 to $8 \mathrm{~mm}$, and were negative for neoplastic degeneration. Conventional rats showed this feature to a lesser extent $(33.33 \%)$.

Systemic immune response after cancer induction. In this preliminary study, we also investigated the possible effects of GF and CV conditions on the systemic immunity after cancer induction. We evaluated the variations in the principal lymphoid cell subpopulation at the mesenteric lymph nodes (MLNs), spleen and blood levels, and the cytotoxic activity of blood- and spleen-derived mononuclear cells. 


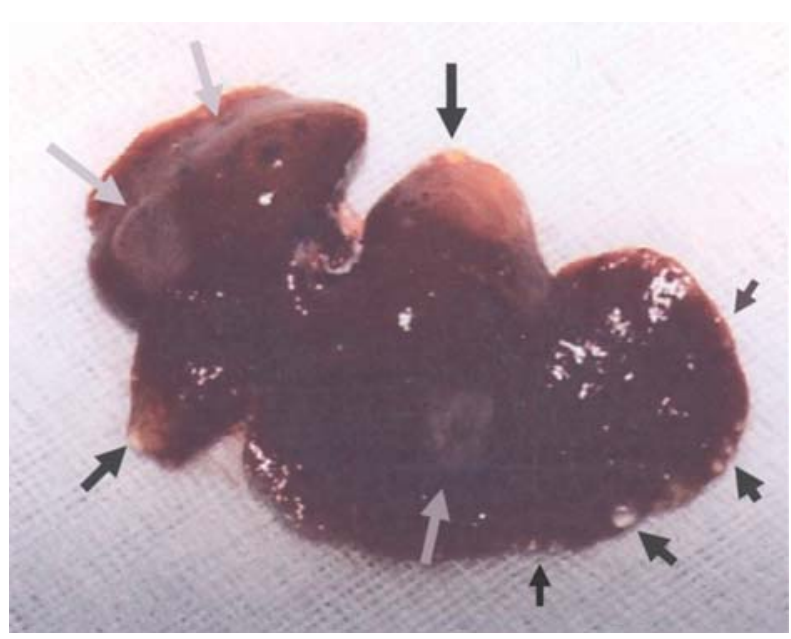

Figure 5. Polycystic liver in GF rats. The cysts have a variable distribution in the organ with variable dimensions (arrows).

NK and NKT cells. NK lymphocytes are crucial effectors of the innate immune response during carcinogenesis, and, together with NKT cells, they assist in the development of a correct adaptive anticancer immunity in a cross-talk with dendritic cells $(37,38)$. Comparing the GF and CV rats, the percentages of both NK and NKT lymphocytes in the MLNs were very similar both in the healthy and cancer-induced animals (Fig. 6).

Also in the spleen, the NK and NKT cell values followed similar dynamics in both $\mathrm{CV}$ and GF rats; the values in the GF animals being constitutively higher (Fig. 6D and E).

In the blood, on the other hand, the NK cells of GF rats markedly rose in the cancer-resistant group (146\% of the healthy control value and $194.83 \%$ of the $\mathrm{CV}$ value; $\mathrm{t}=0.03$ )
(Fig. 6C-F), and a 60\% increment of NKT cells was also observed after cancer induction (Fig. 6).

$T$ and $B$ lymphocytes. Variation in the number of adaptive immunity cell subpopulations can be indicative of the capability and efficacy of the immune response mounted by an organism against a developing cancer.

In the spleen and blood, the T lymphocytes of GF animals paralleled the dynamics observed in $\mathrm{CV}$ rats; at lower values but with a similar trend. However, in the blood, the GF (but not the CV) cancer-resistant rats showed a $27 \%$ increment over the control value (Fig. 7A-C). In contrast, in the MLNs the response to the carcinogenesis induced an increase in $\mathrm{T}$ lymphocytes in CV rats and a minor decrease in GF rats.

The B cells presented opposite dynamics (Fig. 7D-F). No differences between the groups were found in the spleen, while in the blood, the GF cancer-resistant group exhibited a rise in B cells, $40 \%$ over the control and $70 \%$ over the $\mathrm{CV}$ group $(\mathrm{t}=0.01)$.

$C D 4^{+} T$ helper and cytotoxic $T$ lymphocytes. On evaluating the two principal $\mathrm{T}$ cell subpopulations involved in the immune response, the $\mathrm{CD}^{+}$(T helper, Fig. 8A-C) and $\mathrm{CD}^{+}$ (CTL, Fig. 8D-F) lymphocytes, the dynamics of $\mathrm{CD}^{+}$cells in the spleen and in the MLNs paralleled that described in the T lymphocytes.

In the blood, on the other hand, the $\mathrm{CV}$ animals had quite stationary values of $\mathrm{CD}^{+}$cells (with a slight reduction in cancer-bearing rats), while the GF rats showed a progressive increase in the $\mathrm{CD}^{+}$cell percentages from the healthy to the cancer-bearing group (114\% in the cancer-resistant group, $143 \%$ in the cancer-bearing rats, $\mathrm{t}=0.01$; control, 100).

The CTL subpopulation responded differently in the two conditions. In MLNs, the CTL increased $47 \%$ in the cancerresistant $\mathrm{CV}$ rats, and maintained quite normal values in the
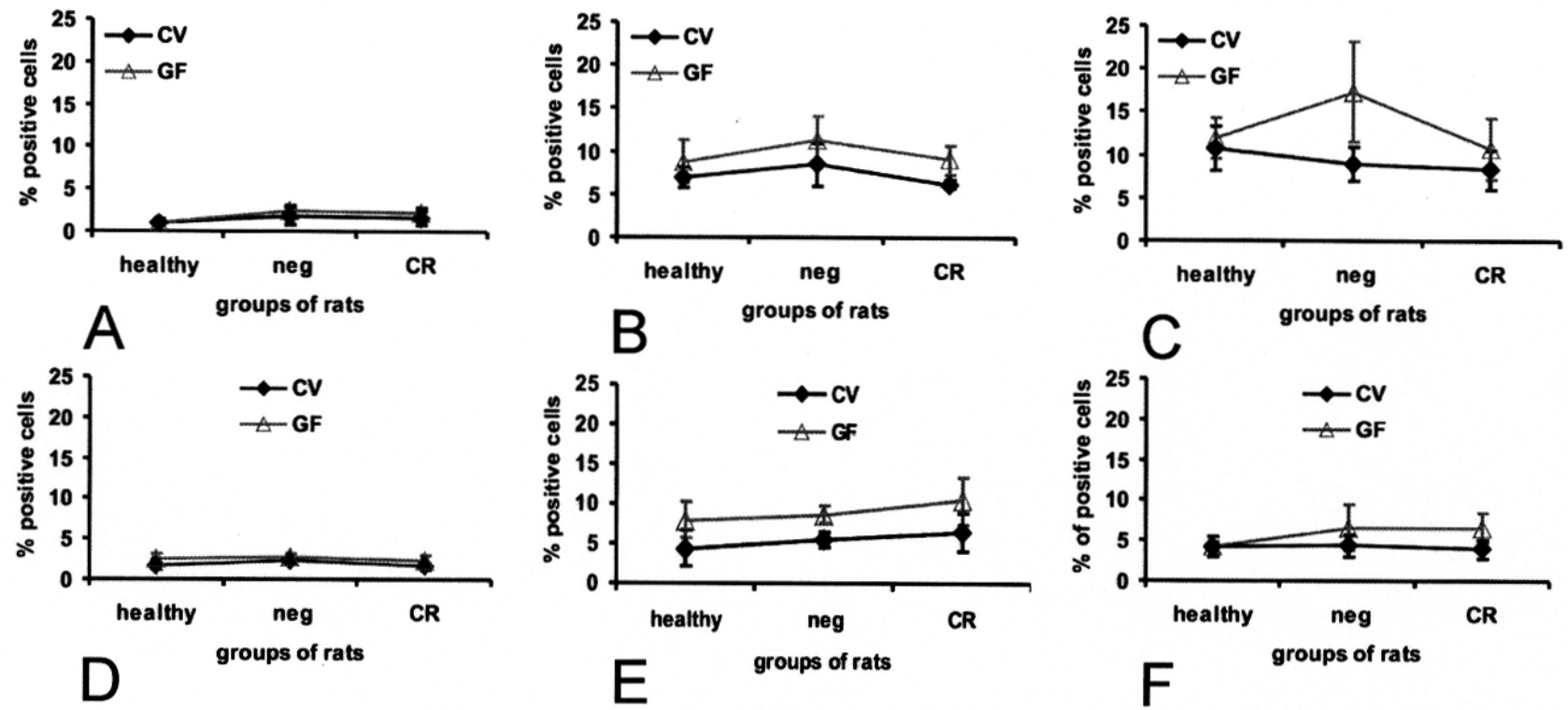

Figure 6. NK and NKT cells after cancer induction. (A-C) NK lymphocytes; (D-F) NKT lymphocytes. Percentages of positive cells in mesenteric lymph nodes (A and D), spleen (B and E), and blood (C and F). NK cells were identified as CD3/NKR-P1Ahigh/CD8a ${ }^{+}$; NKT cells were identified as $\mathrm{CD}^{+} / \mathrm{TCR} \alpha \beta^{+} / \mathrm{NKRP} \mathrm{A}^{+}$. Healthy, control group; neg, rats negative for tumor development after carcinogenesis induction (cancer-resistant); CR, cancerbearing rats. 

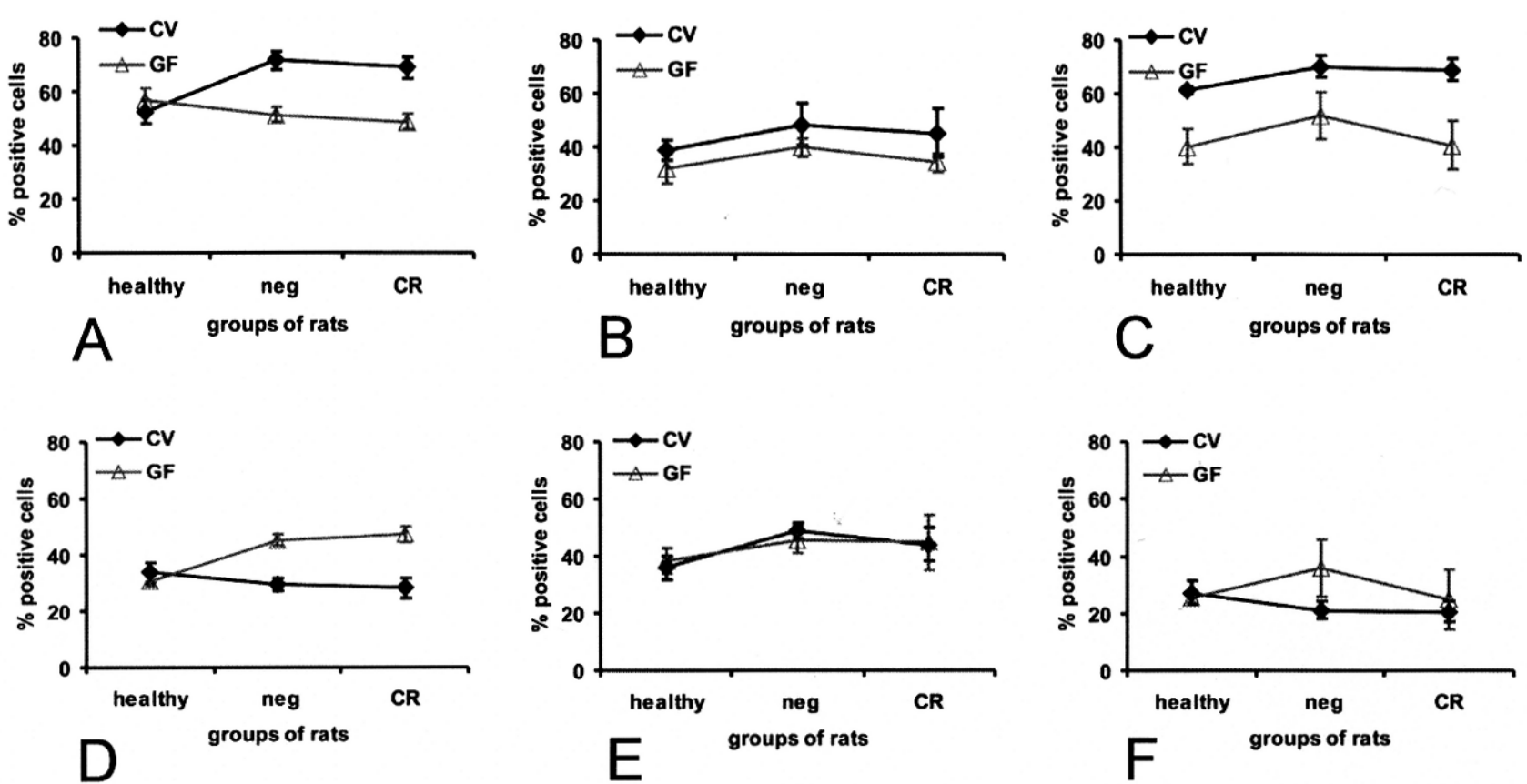

Figure 7. T and B lymphocytes after cancer induction. (A-C) T lymphocytes; (D-F) B lymphocytes. Percentages of positive cells in mesenteric lymph nodes (A and D), spleen (B and E), and blood (C and F). T lymphocytes were identified as CD3+/TCR $\alpha \beta^{+} / \mathrm{NKR} \cdot \mathrm{P} 1 ;$; B cells were identified as $\mathrm{CD} 3 / \mathrm{CD} 45 \mathrm{ra}^{+}$. Healthy, control group; neg, rats negative for tumor development after carcinogenesis induction (cancer-resistant); CR, cancer-bearing rats.
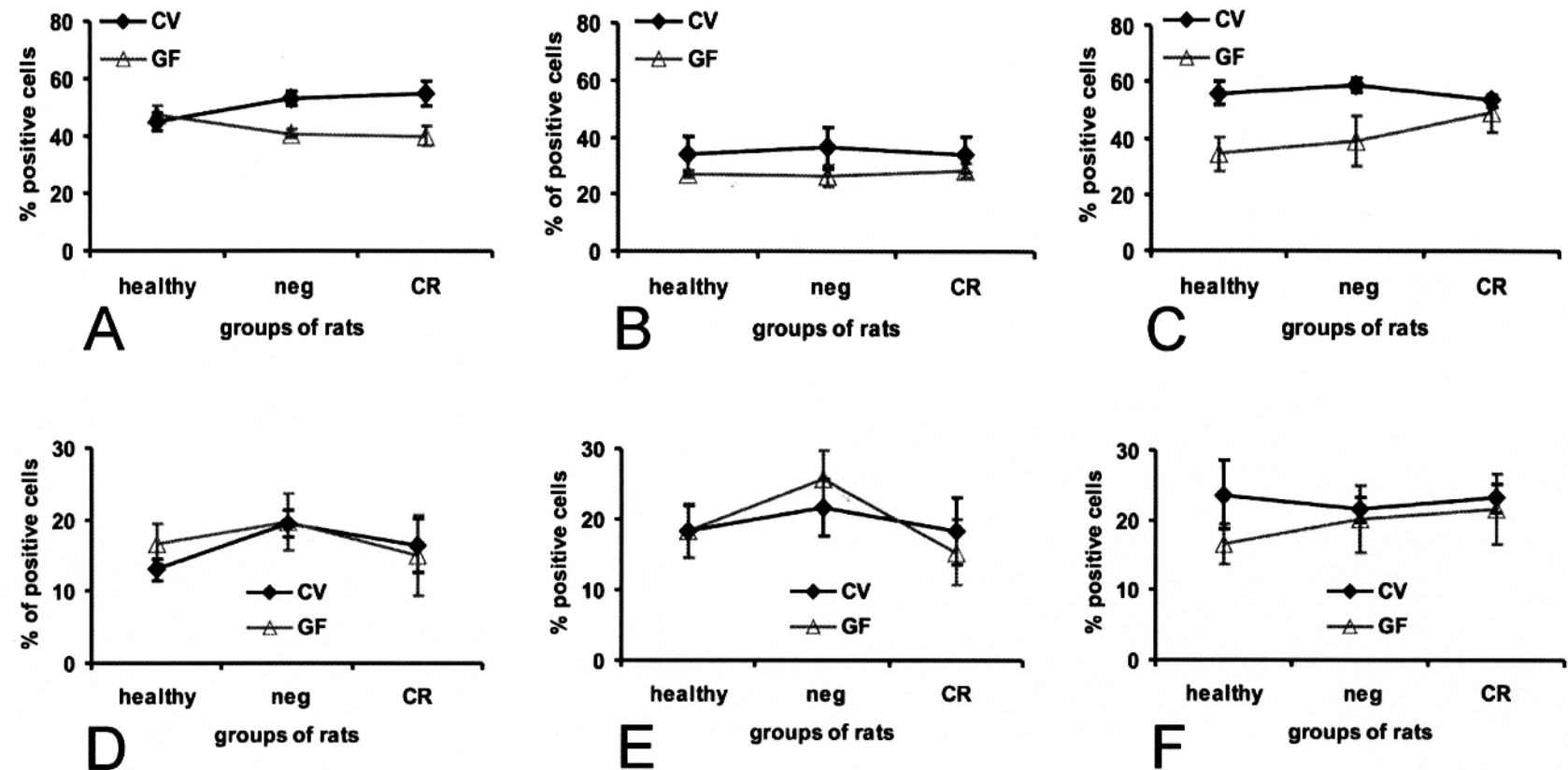

Figure 8. CD4+ $\mathrm{T}$ helper and CTL lymphocytes after cancer induction. (A-C) CD4+ $\mathrm{T}$ helper lymphocytes; (D-F) CTL lymphocytes. Percentages of positive cells in mesenteric lymph nodes ( $\mathrm{A}$ and $\mathrm{D}$ ), spleen (B and E), and blood ( $\mathrm{C}$ and F). T helper lymphocytes were identified as $\mathrm{CD}^{+} / \mathrm{CD}^{+} / \mathrm{CD} 8 \mathrm{~b}$; $\mathrm{CTL}$ lymphocytes were identified as $\mathrm{CD} 8 \mathrm{a}^{+} / \mathrm{CD} 8 \mathrm{~b}^{+}$. Healthy, control group; neg, rats negative for tumor development after carcinogenesis induction (cancerresistant); CR, cancer-bearing rats.

GF rats. The cancer development caused a decrease in CTL in both $\mathrm{GF}$ and $\mathrm{CV}$ rats.

In the spleen, while the CTL values of the CV rats did not show significant variations in the three groups, the GF rats presented a $44 \%$ increase in the resistant-to-cancer group $(\mathrm{t}=0.1)$ and a $20 \%$ reduction in cancer conditions.
The blood CTL levels were enhanced by $20 \%$ in the GF rats after carcinogenesis, while only slight variations occurred in the values of the $\mathrm{CV}$ rats.

Cytotoxicity. The cytotoxic activity against the YAC-1 cells (rat lymphoma cell line sensitive to the cytotoxic activity of 

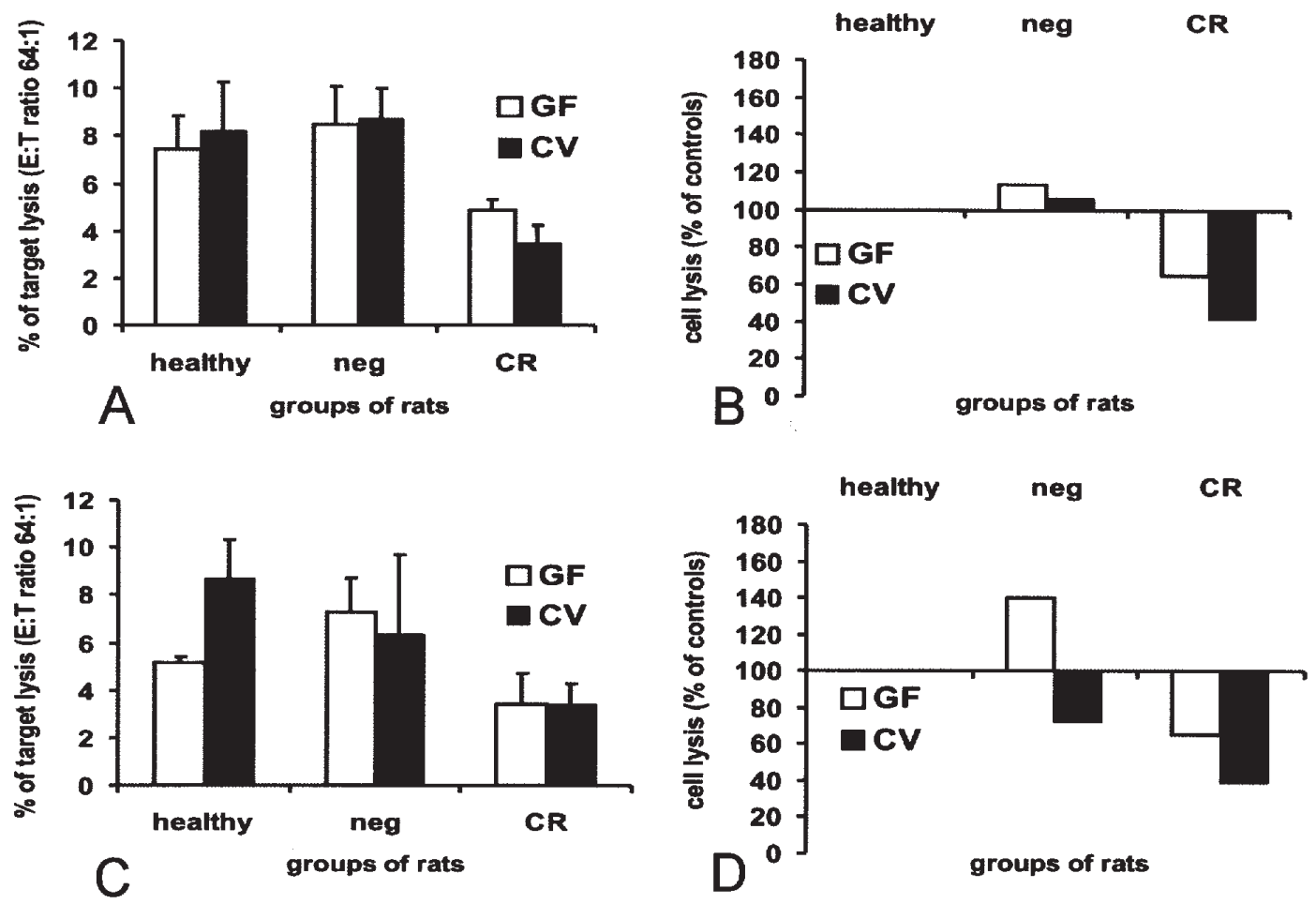

Figure 9. Cytotoxicity after cancer induction. Tests were performed in duplicate. Effector:target ratio (E:T) 64:1; $3.5 \mathrm{~h}$ assay. Spleen (A and B); blood (C and D). The values in B and D are shown as percentages of the control. Healthy, control group; neg, rats negative for tumor development after carcinogenesis induction (cancer-resistant); CR, cancer-bearing rats.

NK) was evaluated in the spleen and in the blood mononuclear cells. In the spleen (Fig. 9A and B), the cytotoxicity did not show significant differences between $\mathrm{CV}$ and $\mathrm{GF}$ healthy and cancer-resistant animals. In contrast, an established cancer condition produced important impairment of the cytotoxic function, larger in $\mathrm{CV}$ than in $\mathrm{GF}$ animals (-58 vs $-35 \%$ of healthy controls, respectively). In the blood (Fig. 9C and D), the circulating lymphocytes of GF rats had enhanced activity in cancer-resistant animals $(140 \%$ of control vs $72.5 \%$ of the control in the CV animals, $t=0.01$ ) and they were less inhibited in the cancer-bearing rats than in the CV group (-35 vs $-60 \%$ respectively).

\section{Discussion}

Applying the same model of carcinogenesis in the same strain of rats under CV and GF conditions, we found that GF rats show a lower susceptibility to inducing and developing colorectal cancers, and a more active anticancer immune response than $\mathrm{CV}$ rats.

Similar results about cancer development in GF animals were previously reported by other authors. It was found that GF rats can develop less and smaller solid tumors (including colorectal tumors) than CV animals, both spontaneously and after chemically induced carcinogenesis with either 1,2dimethylhydrazine (DMH) or its active derivatives AOM and methylazoxymethanol. This different susceptibility was attributed to the important contribution of bacterial populations to the development of the carcinogenetic process (39-41). Reddy et al reported that only $20 \%$ of GF rats develop tumors after DMH. In contrast, the tumor incidence in CV rats was $93 \%$, and the neoplasms were multiple. The authors found the contamination of gnotobiotic rats with Clostridium perfrigens to be relevant for colonic carcinogenesis. Notably, they also observed that GF rats did not develop ear tumors, a common event in hydrazine-derivative cancer induction under CV conditions (42). Depending on the type of diet, the commensal microbiota (especially the component anaerobic bacteria) can be modified, with effects on the metabolism of the alimentary and biliary substrates. McGarr et al stressed the importance of the bacterial flora composition in conditioning the intestinal environment by its metabolic products (production of bile acid $7 \alpha$-dehydroxylation, sulfidogenesis, methanogenesis, and related changes in the carbohydrate and bile acid metabolism) (4). The bile metabolism appeared important in many experimental and clinical reports. The bile secreted after administration of DMH induced an intense enhancement of the $\beta$-glucuronidase activity in intestinal bacteria of cancer-induced rats, and variations in the bile metabolism (also according to the fat intake with the diet) were associated to hyperplasia of mucosal crypts in the colon $(27,43-47)$. The absence of bacteria in GF rats eliminates all of these noxious factors and limits the effects of the carcinogenesis.

The intestinal microbiota were also demonstrated to affect the development and maturation of the mucosal immune system, with pronounced effects on local and systemic immune responses $(10,15,17,48,49)$.

Our data, though preliminary, indicate a different capability of GF versus $\mathrm{CV}$ rats to mount an efficient immune response against cancer. The values of the immune cell subpopulations in the blood of GF animals that were induced to cancer but 
did not develop tumors suggest that the challenge i) enhanced the immunity of GF rats, increasing the NK and NKT lymphocytes and ii) stimulated the establishment of a valid adaptive immune response increasing the number of both the CTL and B cells. The increased cell number was associated with an augmented cytotoxic function. In CV rats, on the other hand, the blood immunological parameters did not show appraisable variations from the healthy condition values.

The particular interplay between the microbiota and the mucosal immune system in the bowel can explain these findings. The intraepithelial diffuse lymphocytes, intramucosal and submucosal follicles and patches constitute a system that represents an extensive, important and plastic barrier against the penetration of foreign organisms (bacteria, fungi, viruses, and parasites) through the mucosal epithelia inside the organism $(10,15)$. How this barrier works is still a matter of discussion. The role of $\mathrm{T}$ and $\mathrm{B}$ cells in the mucosa, the $\mathrm{T}$ helper cell activity to sustain IgA-producing B cells, as well as the continuous production of $\operatorname{IgA}$ targeting the commensal microbiota are aspects that are nearly clarified, whereas the effect of this interplay on the systemic immunity is still controversial (50-53). Certainly, the variable spectrum of antigens exhibited by the various types of microbiota (and their metabolic products) can variably challenge the immunity and the tolerant immune environment of the gut. However, the DC and T-helper cell cross-talk with the epithelial cells and bacteria, the modulation of the cytokine balance (Th1, Th2, Th3 cytokines) and the Toll-like receptor involvement may produce effects also influencing the systemic immunity $(10,11,13,16,51)$. For example, the bacterial environment developing in newborns (passing from the uterine germ-free conditions to the contaminated extrauterine world) is tightly connected with the type of lactation and the composition of the maternal milk with its immunologically active factors (IgA, cytokines, and insulin-type fructans). Consequently, early nutrition can have an impact on both the development of bacterial flora and the maturation and antigen tolerance of the immune system (local and systemic) $(11,51,54)$.

Antigen tolerance is also dependent on the function of $\mathrm{T}$ regulatory lymphocytes $\left(\mathrm{CD} 4^{+} \mathrm{CD} 25^{+} \mathrm{Foxp}^{+}\right)$of the lamina propria and a special population of DCs characterized by the production of IL-10, able to polarize T cells to become regulatory cells producing IL-4, IL-10 and TGF- 3 . They migrate in the Peyer's patches and in the MLNs where the tolerance to antigens derived from the alimentary tract is developed. Their function has a particular role in controlling the homeostasis in the bowel by maintaining a tolerant environment leading also to systemic tolerance and/or IgA production $(53,55,56)$.

In our experimental conditions, the difference in the response observed between GF and $\mathrm{CV}$ rats suggests the importance of the exposure to a multitude of antigens for inducing a more tolerant environment in the $\mathrm{CV}$ than in the GF animals. We can hypothesize that the continuous immunological activation to contain the commensal flora assault $(13,48)$, together with the bacterial antigens and the variable production of metabolites by the diet- and drug-selected bacterial populations may considerably increase the spectrum of tolerated antigens. The resulting tolerant environment might override the capability to promptly respond to transformed cells. Because of the much lower antigenic exposure, the immune system of GF rats may represent a more naïve system not impeded by the regulatory mechanisms controlling the 'physiological inflammation'. This condition may help to develop a correct sequence of immune responses leading to further maturation of the immunity (increase in the number of cytotoxic and regulatory lymphocytes) and a better establishment of the anticancer adaptive response (increase in CTL and B cells) also at the systemic level (blood). In the MLNs, CV and GF animals demonstrated opposite dynamics; the $\mathrm{CV}$ rats showed increased $\mathrm{T}$, T helper and NKT cells and a reduction in $\mathrm{B}$ lymphocytes, while the GF rats showed an increase in CTL and B cells and a reduction in $\mathrm{T}$ and $\mathrm{T}$ helper lymphocytes. Further studies are needed to better define the phenotype of these cells and the cytokine and antibody profile.

In conclusion, we can assume that GF rats have a better capability to elicit anticancer immune responses than $\mathrm{CV}$ animals, and that the immunological challenge produced by the intestinal microbiota and its products can develop a double-edged effect on cancer development. These data are promising for addressing the possible use of prebiotics and probiotics in inducing modulations of the systemic immunity.

\section{Acknowledgements}

This study was funded by grants nos. IAA500200509, IAA500200510 and S500200572 of the Grant Agency of the Academy of Sciences of the Czech Republic, no. 303/06/0974 of the Grant Agency of the Czech Republic, no. 2B06155 of the Ministry of Education of the Czech Republic, by ARPA Foundation, Pisa, (IT), and by the Institutional Research Concept no. AV0Z50200510.

\section{References}

1. Ferlay J, Autier P, Boniol M, Heanue M, Colombat M and Boyle P: Estimates of cancer incidence and mortality in Europe in 2006. Ann Oncol 18: 581-592, 2006.

2. Potter JD: Risk factors for colon neoplasia - epidemiology and biology. Eur J Cancer 31A: 1033-1038, 1995.

3. Le Marchand L, Wilkens LR, Hankin JH, Kolonel LN and Lyu LC: Independent and joint effects of family history and lifestyle on colorectal cancer risk: implications for prevention. Cancer Epidemiol Biomarkers Prev 8: 45-51, 1999.

4. McGarr SE, Ridlon JM and Hylemon PB: Diet, anaerobic bacterial metabolism, and colon cancer: a review of the literature. J Clin Gastroenterol 39: 98-109, 2005.

5. Hope ME, Hold GL, Kain R and El-Omar EM: Sporadic colorectal cancer - role of the commensal microbiota. FEMS Microbiol Lett 244: 1-7, 2005.

6. Horie H, Kanazawa K, Kobayashi E, Okada M, Fujimura A, Yamagiwa S and Abo T: Effects of intestinal bacteria on the development of colonic neoplasm. II. Changes in the immunological environment. Eur J Cancer Prev 8: 533-537, 1999.

7. Guarner F and Malagelada JR: Gut flora in health and disease. Lancet 361: 512-519, 2003.

8. Marteau PR, de Vrese M, Cellier CJ and Schrezenmeier J: Protection from gastrointestinal diseases with the use of probiotics. Am J Clin Nutr 73: 430S-436S, 2001.

9. Geier MS, Butler RN and Howarth GS: Probiotics, prebiotics and synbiotics: a role in chemoprevention for colorectal cancer? Cancer Biol Ther 5: 1265-1269, 2006.

10. Cebra JJ, Jiang H-Q, Boiko $\mathrm{N}$ and Tlaskalova-Hogenova H: The role of mucosal microbiota in the development, maintenance, and pathologies of the mucosal immune system. In: Mucosal Immunology. Mestecky J, Bienenstock J, Lamm ME, Mayer L, McGhee JR and Strober W (eds). 3rd edition, Elsevier/ Academic Press, Amsterdam, pp335-368, 2005. 
11. Christensen HR, Frokiaer H and Pestka JJ: Lactobacilli differentially modulate expression of cytokines and maturation surface markers in murine dendritic cells. J Immunol 168: 171-178, 2002

12. Tlaskalova-Hogenova H, Sterzl J, Stepankova R, Dlabac V, Vetvicka V, Rossmann P, Mandel L and Rejnek J: Development of immunological capacity under germfree and conventional conditions. Ann NY Acad Sci 409: 96-113, 1983.

13. Umesaki Y and Setoyama H: Structure of the intestinal flora responsible for development of the gut immune system in a rodent model. Microb Infection 2: 1343-1351, 2000

14. Maaser $C$ and Kagnoff MF: Role of the intestinal epithelium in orchestrating innate and adaptive mucosal immunity. Z Gastroenterol 40: 525-529, 2002.

15. Tlaskalova-Hogenova H, Stepankova R, Hudcovic T, Tuckova L, Cukrowska B, Lodinova-Zadnikova R, Kozakova H, Rossmann P, Bartova J, Sokol D, Funda DP, Borovska D, Rehakova Z, Sinkora J, Hofman J, Drastich P and Kokesova A: Commensal bacteria (normal microflora), mucosal immunity and chronic inflammatory and autoimmune diseases. Immunol Lett 93: 97-108, 2004.

16. Dubois B, Goubier A, Joubert G and Kaiserlian D: Oral tolerance and regulation of mucosal immunity. Cell Mol Life Sci 62: 1322-1332, 2005.

17. Haneberg B, Kendall D, Amerongen HM, Apter FM and Neutra MR: The colon and rectum as inductor sites for local and distant mucosal immunity. Adv Exp Med Biol 1371A: 107-109, 1995.

18. Lijinsky W: Importance of animal experiments in carcinogenesis research. Environ Mol Mutagen 11: 307-314, 1988

19. Vaitukaitis JL: Animal models of human disease for the 21st century. Lab Anim Sci 48: 562-564, 1998.

20. Heijstek MW, Kranenburg O and Borel Rinkes IH: Mouse models of colorectal cancer and liver metastases. Dig Surg 22: 16-25, 2005.

21. Lijinsky W: Intestinal cancer induced by $\mathrm{N}$-nitroso compounds. Toxicol Pathol 16: 198-204, 1988.

22. Reddy BS: Studies with the azoxymethane-rat preclinical model for assessing colon tumor development and chemoprevention. Environ Mol Mutagen 44: 26-35, 2004.

23. Takahashi $\mathrm{T}$, Morotomi $\mathrm{M}$ and Nomoto $\mathrm{K}$ : A novel mouse model of rectal cancer established by orthotopic implantation of colon cancer cells. Cancer Sci 95: 514-519, 2004.

24. Vannucci L, Huggins CB and Mosca F: A new experimental model for colorectal cancerogenesis in the rat. J Environ Pathol Toxicol Oncol 13: 59-61, 1994.

25. Vannucci L, Fiserova A, Horvath O, Rossmann P, Mosca F and Pospisil M: Cancer evolution and immunity in a rat colorectal carcinogenesis model. Int J Oncol 25: 973-981, 2004.

26. Sutherland LA and Bird RP: The effect of chenodeoxycholic acid on the development of aberrant crypt foci in the rat colon. Cancer Lett 76: 101-107, 1994.

27. Weidema WF, Deschner EE, Cohen BI and DeCosse JJ: Acute effects of dietary cholic acid and methylazoxymethanol acetate on colon epithelial cell proliferation; metabolism of bile salts and neutral sterols in conventional and germfree SD rats. J Natl Cancer Inst 74: 665-670, 1985.

28. Tlaskalova-Hogenova H: Gnotobiology as a tool - an introduction. In: Immunology Methods Manual. Lofkovits I (ed). Vol. 3, Academic Press, London, pp1524-1529, 1997.

29. Chocholova L and Kolinova M: A comparison of reactivity of two strains of laboratory rats to drugs and acoustic stimuli. Physiol Bohemslov 31: 258, 1982.

30. Stepankova R: Rearing germ-free rats, mice, and rabbits. In: Immunology Methods Manual. Gnotobiologic Models. Lefkovits I, Tlaskalova H and Sterzl J (eds). Vol. 3, Academy Press, New York, pp1537-1542, 1997.

31. Stepankova R, Sinkora J, Hudcovic T, Kozakova $H$ and Tlaskalova-Hogenova H: Differences in development of lymphocyte subpopulations from gut-associated lymphatic tissue (GALT) of germ-free and conventional rats: effect of aging. Folia Microbiol 43: 531-534, 1998.

32. Stepankova R, Dvorak B, Sterzl J and Trebichavsky I: Effects of essential fatty acid deficiency in milk diets in the development of germ-free and conventional rats. Physiol Bohemoslov 39: 135-146, 1990.

33. Dvorak B and Stepankova R: Effects of dietary essential fatty acid deficiency on the development of rat thymus and immune system. Prostaglandins Leucot Essent Fatty Acids 46: 183-189, 1992.
34. Fazii P, Ciancaglini E and Sforza G: Differential fluorescent staining method for detection of bacteria in blood cultures, cerebrospinal fluid and other clinical speciments. Eur J Clin Microbiol Infect Dis 21(5): 373-378, 2002.

35. Woollet GR, Barclay AN, Puklavec M and Williams AF: Molecular and antigenic heterogeneity of the rat leukocyte common antigen from tymocytes and $\mathrm{T}$ and B lymphocytes. Eur J Immunol 15: 168-173, 1985.

36. Fiserova A, Kovaru H, Hajduova Z, Mares V, Starec M, Kren V, Flieger $M$ and Pospisil $M$ : Neuroimmunomodulation of natural killer (NK) cells by ergot alkaloid derivatives. Physiol Res 46: 119-125, 1997.

37. Zitvogel L, Terme M, Borg C and Trinchieri G: Dendritic cellNK cell cross-talk: regulation and physiopathology. Curr Top Microbiol Immunol 298: 157-174, 2006

38. Moretta A, Marcenaro E, Parolini S, Ferlazzo G and Moretta L: NK cells at the interface between innate and adaptive immunity. Cell Death Differ, June 1, 2007 (Epub ahead of print).

39. Sacksteder MR: Occurrence of spontaneous tumors in the germfree F344 rat. J Natl Cancer Inst 57: 1371-1373, 1976.

40. Reddy BS, Narisawa T and Weisburger JH: Colon carcinogenesis in germ-free rats with intrarectal 1,2-dimethylhydrazine and subcutaneous azoxymethane. Cancer Res 36: 2874-2876, 1976.

41. Reddy BS and Ohmori T: Effect of intestinal microflora and dietary fat on 3,2'-dimethyl-4-aminobiphenyl-induced colon carcinogenesis in F344 rats. Cancer Res 41: 1363-1367, 1981.

42. Reddy BS, Narisawa T, Wright P, Vukusich D, Weisburger JH and Wynder EL: Colon carcinogenesis with azoxymethane and dimethylhydrazine in germ-free rats. Cancer Res 35: 287-290, 1975.

43. Huycke MM and Gaskins HR: Commensal bacteria, redox stress, and colorectal cancer: mechanisms and models. Exp Biol Med 229: 586-597, 2004.

44. Williamson RC, Bauer FL, Ross JS, Watkins JB and Malt RA Enhanced colonic carcinogenesis with azoxymethane in rats after pancreaticobiliary diversion to mid small bowel. Gastroenterology 76: 1386-1392, 1979.

45. Savage AP, Sian MS, Matthews JL, Bloom SR and Cooke T: Experimental colonic carcinogenesis: changes in faecal bile acids after promotion of intestinal tumours by small bowel resection in the rat. Gut 29: 495-502, 1988.

46. Iwasaki I, Iwase H, Yumoto N and Ide G: Promoting effects of bile acid to intestinal tumorigenesis in gnotobiotic ICR mice. Acta Pathol Jpn 35: 1427-1433, 1985

47. Kim DH and Jin YH: Intestinal bacterial beta-glucuronidase activity of patients with colon cancer. Arch Pharm Res 24 564-567, 2001

48. Biancone L, Monteleone I, Del Vecchio Blanco G, Vavassori P and Pallone F: Resident bacterial flora and immune system. Dig Liver Dis 34 (suppl 2): 37-43, 2002.

49. Pickard KM, Bremner AR, Gordon JN and MacDonald TT: Microbial-gut interactions in health and disease. Immune responses. Best Pract Res Clin Gastroenterol 18: 271-285, 2004.

50. Kelly D, Conway S and Aminov R: Commensal gut bacteria: mechanisms of immune modulation. Trends Immunol 26 : 326-333, 2005.

51. Forchielli ML and Walker WA: The role of gut-associated lymphoid tissues and mucosal defence. Br J Nutr 93 (suppl 1): 41-48, 2005 .

52. Cario E and Podolsky DK: Intestinal epithelial TOLLerance versus inTOLLerance of commensals. Mol Immunol 42: 887-893, 2005 .

53. Macpherson AJ, Geuking MB and McCoy KD: Immune responses that adapt the intestinal mucosa to commensal intestinal bacteria. Immunology 115: 153-162, 2005

54. Calder PC, Krauss-Etschmann S, de Jong EC, Dupont C, Frick JS, Frokiaer H, Heinrich J, Garn H, Koletzko S, Lack G, Mattelio G, Renz H, Sangild PT, Schrezenmeir J, Stulnig TM, Thymann T, Wold AE and Koletzko B: Early nutrition and immunity - progress and perspectives. Br J Nutr 96: 774-790, 2006.

55. Makita S, Kanai T, Nemoto Y, Totsuka T, Okamoto R, Tsuchiya K, Yamamoto M, Kimono $\mathrm{H}$ and Watanabe M: Intestinal lamina propria retaining $\mathrm{CD} 4{ }^{+} \mathrm{CD} 25^{+}$regulatory $\mathrm{T}$ cells is a suppressive site of intestinal inflammation. J Immunol 178: 4937-4946, 2007.

56. Mowat A McI: Anatomical basis of tolerance and immunity to intestinal antigens. Nat Rev Immunol 3, 331-341, 2003. 